\title{
MONITORING AND ENVIRONMENTAL MODELING OF EARTHWORK IMPACTS: A ROAD CONSTRUCTION CASE STUDY
}

\author{
Adrien Capony ${ }^{1}$, Bogdan Muresan ${ }^{1 *}$, Michel Dauvergne $^{1}$, Jean-Claude Auriol ${ }^{2}$, \\ Valéry Ferber ${ }^{3}$, Agnès Jullien ${ }^{1}$
}

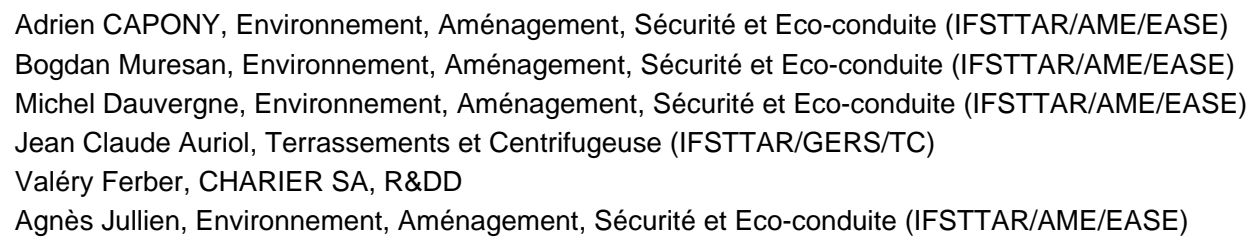

"Corresponding author (Phone: +33 (0)2 408456 35, Fax: +33 (0)2 40845992 , e-mail: bogdan.muresan-paslaru@ifsttar.fr) 
This study presents the contributions of materials, earth engineering equipment and construction techniques to potential environmental impacts from the main items of typical road earthworks. To achieve this goal, the overall activity at a $1.9-\mathrm{km}$ long

51 French earthworks project site for a heavily trafficked highway was surveyed during 52 its 2007-09 construction period. Using data collected and a numerical model of road 53 life cycle assessment (LCA), i.e. ECORCE, six indicators could be evaluated, 54 namely: energy consumption, global warming, acidification, eutrophication, photochemical ozone creation, and chronic human toxicity. When available, several 56 life cycle inventories were implemented in order to appraise indicator sensitivity with 57 respect to the considered panel of pollutants. Results also allowed estimating from an LCA point of view: i) natural resource conservation of both aggregates and soil, during the application of quicklime treatments; and ii) the duration necessary for 60 projected traffic levels to offset the potential environmental impacts of the earthworks 61 stage.

62

63 Keywords: road construction; life cycle assessment; earthwork items; environmental 64 indicators; resource conservation. 


\subsection{Background}

Over the past 15 years, a general consensus has been reached to limit the environmental impacts due to human activity. The United Nations produced a text entitled the "Framework Convention on Climate Change" (or FCCC), which has gathered 192 parties in an effort to stabilize the concentrations of global warming substances in the atmosphere at levels that would prevent dangerous anthropogenic interference with the climate system (UN, 1992). In 1997, the Kyoto Protocol to the FCCC was adopted by 37 countries in order to limit global warming (UN, 1998). Since that time, many agreements have been signed, e.g. a reduction of halogens due to ozone layer depletion (UNEP, 2000), while greater attention has been focused on emitted chemical compounds that increase global acidification, eutrophication and (eco)toxicity. In 2007, the French Grenelle Environment Round Table (http://www.legrenelle-environnement.fr/-Loi-Grenelle-2-.html) led to the creation of 257 articles introduced into laws on various topics, including resource conservation.

On the basis of these new laws, the private sector undertook full-scale testing and entered into private-public partnerships. The one discussed herein, i.e. the TerDouest research program, has been funded by France's National Research Agency (ANR) and conducted by the French Institute of Science and Technology for Transport, Development and Networks (Ifsttar). Support has been provided by Egis, Lhoist, Cimbeton, Charrier, La Forrezienne / Eiffage groups as well as by the French National Railway Corporation (SNCF) and Interdepartmental Directorates of Roads (DIR - Centre Region) in order to achieve these objectives. In this context, the present study examines earthwork activity for the purpose of appraising work practices through an impact assessment. 
91 Due to the complexity of non-road equipment operating conditions, the difficulty of in 92 situ data collection and the multiplicity of impacts, the risk of environmental degradation creates an unavoidable challenge in the area of earthworks, which affect both the local and global environment by: i) erecting barriers that fragment habitats; ii) modifying the interactions between organisms, e.g. noise generation that may drown out birds' singing during breeding periods or night lighting that modifies den sites and hunting spots for chiroptera; iii) affecting $\mathrm{pH}$ and redox conditions of soil, water and air due to treatments with various binders; and iv) producing global warming and/or (eco)toxic compounds due to the fuel burned in machines, with these compounds being transferred into various compartments of the ecosphere. To gauge the impacts of earthworks, a larger dataset is thus required than the datasets derived for aggregate extraction (Jullien et al., 2012) or for asphalt pavement construction assessment (Jullien et al., 2006). Any extensive environmental consideration relative to earthworks is difficult to achieve without introducing life cycle modeling tools. To the best of our knowledge, only a small amount of research has dealt with the entire life cycle of earthwork activity (Xiaodong et al., 2008, 2010) or material use (Mroueh and Wahlström, 2002; Stripple, 2001).

\subsection{Objectives}

110 In accordance with the French Grenelle Environment Round Table (2007), this study 111 seeks to:

112 i) draw environmental conclusions on earthwork practices, to be accomplished by surveying the relative contributions of the various items composing a typical earthworks project (with a distinction made between materials and machinery), regarding energy consumption and potential environmental impacts; 
ii) understand the main parameters governing the potential impacts of local technical choices, e.g. soil treatment using quicklime. This objective implies defining an alternative technical solution for road structures and designs that had not been proposed in the RN7 development plan (for natural aggregates);

iii) propose solutions for mitigating potential earthworks impacts, to be performed by analyzing results obtained on every single earthwork item and then comparing technical solutions to a reference case: the RN7 projected road traffic.

124 To achieve these objectives, the Life Cycle Assessment (LCA) methodology was applied to elementary earthwork tasks responsible for generating quantifiable environmental impacts. Since databases in the literature provide no detailed

127 inventories for pollutants emitted from earthworks and resource consumption, an extensive data collection effort took place on the study site. These data were then analyzed in order to evaluate the potential environmental impacts of the main phases

130 observed during the earthworks stage of road construction. These phases

131 encompass: i) production and transportation constraints relative to fuel and materials;

132 ii) study area design, which is responsible for determining the project's earthwork volumes; and iii) construction, which includes the work and emissions generated from

134 machinery. This dataset also allowed estimating from an LCA perspective: i) the 135 relative impacts of machines and materials implemented, ii) the conservation of 136 natural aggregate resources when using quicklime treatments as a substitute, and iii)

137 the duration required for road traffic to offset the potential environmental impacts of 138 the earthworks stage. 


\section{$142 \quad 2.1$ The study area}

143 Earthworks on French National Highway 7 (i.e. RN7) constituted the first stage of

144 building an 8.9-km section of highway with two lanes in each direction. The study 145 area was contained within this RN7 development plan, consisting of a 1.9-km long 146 strip designed to relieve urban traffic, as shown at the bottom of Figure 1 (from the

1470.76 to the 2.66 milepost, i.e. MP). Adjoining the study area, the longitudinal (left148 hand side) and transverse (right-hand side) views of the earthworks structure are

149 depicted at the top of Figure 1. Throughout the remainder of this text, we will refer to 150 the main earth categories constitutive of these earthworks as "earthwork items"; they 151 comprised the quicklime-treated fills, treated sub-base layers, enriched soils (i.e. the

152 humic layer of the initial topsoil being stored and then used to re-vegetate the road 153 shoulders and earthen retaining walls prior to completion of the earthworks stage), 154 and the unusable cuts. The aggregate base and base course have not been 155 considered herein. These items are part of the pavement and/or uppermost layers 156 supporting the road and therefore involve different construction techniques and 157 imported materials.

159 The RN7 earthworks phase lasted more than 3 years (from end of June 2006 to

160 December 2009). During this period, over one million cubic meters of earth were 161 engineered (i.e. either transported from their original position or locally processed) 162 and 10 pools were excavated to reduce runoff water loading with particles and 163 associated pollutants. RN7 geology is depicted by coarse-grained sandy and clay-silt 164 soils with a clay content locally exceeding $30 \%$ and a wide range of gravels. Such 165 soils are very sensitive to water and thus prone to mechanical damage; they are 
166 typically found in temperate and subtropical regions (e.g. in the loamy basins of

167 former and current rivers) around the world. As regards the study area, a remarkable 168 characteristic was the magnitude of cuts relative to the fills (see Fig. 1). The cuts

169 were primarily located at 1.00 MP and 1.90 MP, whereas the fills occurred close to $1702.66 \mathrm{MP}$, a situation that accounted for increases in both the amounts of unusable 171 cuts and the average distance traveled by the moved earth.

172

173

\subsection{Environmental modeling}

174

2.2.1 Model implementation principles for an earthworks assessment

Within the LCA framework, as initiated by the TerDouest research program in 2008,

176 Ifsttar has developed the ECORCE 1.0 application, which was initially dedicated to

177 pavements (Ventura et al., 2009, 2010) in order to evaluate the potential environmental impacts of earthworks. This new tool considers all engineered road layers and includes the initial construction and maintenance stages of pavements. The ECORCE 2.0 application currently allows for a comparison among various road

181 construction techniques and types of materials employed, focusing on: (i) the 182 composition and structure of the road layers under consideration, (ii) machine 183 quantities and tasks, and (iii) the absence / presence of soil treatments. RN7 184 earthwork practices (implementation of several construction techniques depending 185 on local soil characteristics) have enabled researchers to collect a wide array of data 186 along road project lengths ranging from $150 \mathrm{~m}$ (Jullien et al., 2006) to $1 \mathrm{~km}$ (Stripple, 187 2001) for earthwork items located in the exact same area. This collection method is 188 therefore consistent with the LCA code of practice for comparing technical solutions 189 at the same site; moreover, it complies with the objectives set for both the 190 comparisons of earthwork items and the comparisons of soil treatments and natural 
191 aggregate use. Most earthwork case study assessment protocols do not allow for

192 assessing two different technical solutions in the same place using local data

193 collected during the works, as was the case for the RN7 project.

194

195 To correspond with the LCA practice applied to road pavements, a comparison is

196 usually performed among several solutions that offer similar services. In this case,

197 ECORCE has been applied to calculate a set of environmental data regarding the 198 various earthwork items providing complementary services, i.e. treated fills, treated

199 sub-base layers, enriched soils, and unusable cuts. Such items support the RN7 200 project in the form of substrates or abutments (enriched soils and unusable cuts are 201 typically stored as earthen retaining walls adjacent to the road).

2.2.2 Building flows databases for the ECORCE application

The ECORCE application was implemented in order to perform a dual assessment of materials, i.e. those introduced for road infrastructure construction and those produced by earthmoving. This implied combining the available Life Cycle Inventories (LCI) for both the quicklime and natural aggregates put to use (Jullien et al., 2012). Such a combination considers two inputs: i) French site data for materials production, and ii) energy content relative to the appropriate production (i.e. French energy and

210 diesel production from the ELCD database, 2002-2003). As regards quicklime 211 production, several distinct LCls were independently examined and consulted in 212 order to determine the sensitivity of indicators for the considered panel of pollutants. 213 Two datasets by Stripple (2001) and Ecoinvent (2002) were initially available at the 214 international scale (see Table 1). Since the French manufacturing processes were 215 not available in either of the international datasets, the French Union of Lime 
216 Producers performed an LCl suited to quicklime production in France (UPC, 2010);

217 this inventory differed by offering: a broader array of quicklime production plants,

218 technological achievements, and a complete list of flows (Table 1). Despite including 219 fuel and energy production, this new LCl exhibits significantly lower energy 220 consumption and $\mathrm{CO}_{2}$ emissions than Stripple's. In comparison, Ecoinvent's $\mathrm{LCl}$ 221 values more closely resembles those of UPC, which suggests that in order to assess 222 the variability of environmental impacts from quicklime production with LCA, a first step may consist of limiting the scope to the LCls derived by Stripple and UPC.

For the 3-year data collection period, the organization of earthworks was scrutinized by separating both the materials and onsite energy consumption. Daily cut and fill volumes were analyzed for every single earthwork item (upper part in Fig. 2), an approach that made it possible to assess: fuel consumption by type of machine, daily work and the corresponding earthwork item (lower part in Fig. 2). This task proved complex since the work completed by all earthmoving equipment cannot be easily

231 isolated at any one time since all materials excavated and compacted are being 232 moved continuously.

\subsubsection{System boundaries and data limitations}

235 Since this study focuses on the completed earthwork items and materials employed, 236 the upstream processes (not directly related to the earthwork input / output flows) 237 have not been included in calculations, i.e. of either machine production or the construction of quarry equipment for treating aggregates. 
240 The LCA for the constructed earthwork items was performed by applying ECORCE 241 with inventories for the various materials employed, machine emissions and 242 production and distribution of consumed energy (grayish zone in Fig. 2). The list of 243 chemical substances available in the ECORCE application has been generated from 244 LCls dedicated to aggregates (Jullien et al., 2006, 2012), bitumen (Eurobitume, 245 1999), cement (Ecobilan, 2002), quicklime (UPC, 2010) and steel (IISI, 1999). 246 Depending on company practices, these LCA calculations were typically conducted 247 in considering a $1-\mathrm{m}^{3}$ functional unit of earth.

249 The atmospheric emissions of chemical substances from machines were estimated 250 from daily fuel consumption data, along with the emission factors for heavy-duty 251 vehicles (Hugrel and Joumard, 2006). Consequently, these merely consisted of daily average data. However, since uncertainties have not been assigned to data available in the literature, research is currently underway in our laboratory to evaluate variations in the emission factors of earthwork machinery as a function of activity and in situ geomorphic / pedological conditions that have not been considered herein.

2.2.4 Indicators description for earthwork assessment

The ECORCE application calculates six environmental indicators (Ventura et al., 2009, 2010) (Table 2), namely: energy consumption (EE, in MJ), global warming potential (GWP, in kg eq. $\mathrm{CO}_{2}$, IPCC, 2001), acidification potential (AP, in $\mathrm{kg}$ eq. $261 \mathrm{SO}_{2}$, Goedkoop, 2001), the eutrophication index (El, in kg eq. $\mathrm{PO}_{4}$, Goedkoop, 262 2001), photochemical ozone creation potential (POCP, in kg eq. $\mathrm{C}_{2} \mathrm{H}_{4}$, Goedkoop, 2001), and chronic human toxicity potential (TP, in kg eq. 1.4 DCB, Huijbregts et al., 264 2000). Throughout this text, we will refer to the selected panel of indicators as $I_{6}$. 
265 Except for energy, all of the indicators introduced have been formulated in 266 accordance with Bare and Gloria (2008) and Bare (2010) as linear combinations of 267 weighted contributions of emissions:

$$
\mathrm{I}_{\mathrm{j}}=\sum_{\mathrm{i}=1}^{\mathrm{n}} \mathrm{a}_{\mathrm{i}}^{\mathrm{j}} \mathrm{C}_{\mathrm{i}}^{\mathrm{j}} \mathrm{m}_{\mathrm{i}}
$$

269 where $l_{j}$ is the indicator relative to potential environmental impact "j" (e.g. GWP), $\alpha_{i}^{j}$ 270 the allocation factor of emission "i" to each individual impact category (unitless [0-1], 271 Sayagh et al., 2010), $C_{i}^{j}$ the individual contribution coefficient of emission "i" to "j" 272 (indicator units: $\mathrm{kg}^{-1}$ ), and $\mathrm{m}_{\mathrm{i}}$ the mass of "i" released into the environment per $\mathrm{m}^{3}$ of 273 moved earth or ton of material used (including production, transportation and 274 application). The values of these contribution coefficients are provided in Goedkoop 275 (1996), Huijbregts et al. (2000) and IPCC (2007).

\section{RESULTS}

\subsection{Model inputs: moved/engineered earth volumes and material inflows}

A design in accordance with anticipated geotechnical characteristics (CSTCN, 1988) of the various earthwork items was investigated so as to analyze engineered earth volumes and amounts of imported materials introduced. The figures obtained are

282 given in Table 3. The geotechnical characteristics of soils at the study site as well as 283 for all RN7 earthworks were initially found to be insufficient for local reuse without 284 preliminary treatment. The soil moisture content was too high (roughly $8 \%-10 \%$ $\mathrm{m} / \mathrm{m}$ ): the compaction curves developed from standard Proctor compaction tests indicated that the optimal moisture content was between $6 \%$ and $8 \%$. The local soils 287 were therefore classified as water sensitive according to the French P11-300 288 standard. 
290 Quicklime $(\mathrm{CaO})$ is commonly used to lower the moisture content of engineered 291 earth. Due to the high moisture content of local soils, quicklime was imported and 292 then added to the fills and sub-base layer. In the presence of water, $\mathrm{CaO}$ forms 293 slaked lime, i.e. $\mathrm{Ca}(\mathrm{OH})_{2}$, within a few minutes of an exothermic reaction. The 294 emitted energy (1160 MJ t-1) results in both a significant temperature rise of the 295 treated soils and a higher dry solid content due to subsequent evaporation: the 296 moisture content decrease is assumed to be proportional to the percentage of added 297 quicklime (a 1\%-to-1\% correspondence). For this reason, the geotechnical 298 characteristics (such as bearing capacity) of treated soils is locally enhanced. The 299 additional amounts of quicklime were determined according to figures in the log kept 300 for managing all daily construction activities, i.e. the quantities and durations of work, 301 type of activities, equipment implemented, and amounts of materials and supplies 302 received. These quicklime amounts equaled $1 \%-2 \%(\mathrm{~m} / \mathrm{m})$ of the engineered earth.

304 Due to quicklime treatments and the ensuing improvement in bearing capacity of 305 treated soils, the aggregates imported from local quarries represented $<10 \%$, i.e. $30619,200 \mathrm{~m}^{3}$, of the volume of engineered earth (Table 3). This imported amount rose 307 to approx. $30 \%$ and $40 \%$ when used as lateral reinforcement for the treated sub-base 308 layer and drainage course under the treated fills, respectively (Fig. 1). The remaining 309 volume of aggregates, i.e. estimated at $6,000 \mathrm{~m}^{3}$, was primarily used to construct the 310 basins receiving surface water discharges. In order to reduce uncertainties, the 311 imported aggregates (small amounts used at the RN7 site) were not taken into 312 consideration during the LCA of earthwork items. 


\subsection{Model inputs: earth movements and in situ fuel consumption}

316 The average distance crossed by moved earth (L) was determined for every single

317 earthwork item included in the study area and RN7 earthworks. Based on fuel tank 318 capacity and their refill frequency, the daily fuel consumption could be evaluated for

319 the two main categories of earth engineering equipment, namely earth movers (i.e.

320 dumpers and trucks) and earth processers (bulldozers, excavators, graders and

321 vibratory rollers). Once the daily fuel consumption was known, then the total fuel

322 consumption was calculated per cubic meter of moved / engineered earth as well as per earthwork item (Table 4).

325 The value of $\bar{L}$ was determined by using the collected daily data within the time326 location plane for in situ earthmoving machinery. This value was formulated as 327 follows:

$$
\bar{L}_{\text {item }}=\frac{\sum_{\mathrm{i}=1}^{\mathrm{n}}\left(\mathrm{L}_{\mathrm{i}} \mathrm{m}_{\mathrm{i}}\right)}{\sum_{\mathrm{i}=1}^{\mathrm{n}} \mathrm{m}_{\mathrm{i}}}
$$

329 where " $\mathrm{L}_{i}$ " is the distance (measured at the metric scale, in $\mathrm{m}$ ) between the origin and

330 destination of the moved earth, and " $\mathrm{m}_{\mathrm{i}}$ " the amount (in $\mathrm{kg}$ ) of transported material.

331 The soil density considered in Eq. 2 is that of compacted earth after being placed in

332 fills (i.e. 2 tons $\mathrm{m}^{-3}$ ). The density of earth placed in the earth movers was excluded since it may widely vary depending on the geological nature of soils and excavation /

334 extraction methodology implemented (e.g. excavators, loaders, scrapers, bulldozers).

335 The subscript "i" stands for the various earth movements relative to the considered 336 earthwork item. 
338 The formula for $\bar{L}$ implicitly took into account the typology, quantity and load capacity

339 of earthmoving machinery (mostly dumpers, $8-20 \mathrm{~m}^{3}$ capacity). Regarding all 340 machines taken as a whole, the entire RN7 earthworks project (resp. just the 1.9-km 341 study area section) deployed up to 85 (resp. 48) earth engineering machines

342 including, but not restricted to, bulldozers (with a net engine power of $80-480 \mathrm{~kW}$ ), 343 dumpers (220-750 kW), excavators (90-420 kW), graders (130-220 kW), scrapers 344 (270-410 kW), vibratory rollers (110-150 kW) and trucks (180-320 kW).

\subsection{Potential environmental impacts: comparison of earthwork items}

347 Figure 3 shows the contribution of each earthwork item to the potential environmental 348 impacts of the study area. These contributions were calculated using the ECORCE 349 application with Stripple's (top panel) and UPC (bottom panel) quicklime production 350 LCls and the selected $I_{6}$ environmental indicators.

352 Among the various earthwork items, the contribution of unusable cuts to the volume 353 of engineered earth and associated fuel consumption was predominant, i.e. 110,000 $354 \mathrm{~m}^{3}$ (Table 3) and $90.9 \mathrm{~m}^{3}$ (Table 4), respectively, or the equivalent of $\sim 50 \%$ of overall 355 values for the study area. Unlike the treated fills and construction of treated sub-base 356 however, the contribution of unusable cuts to the $I_{6}$ environmental indicators 357 amounted to $5 \%-40 \%$ (Stripple LCI) and 4\%-34\% (UPC LCI), respectively (Fig. 3).

358 This finding confirms that the engineered earth volume and related fuel consumption 359 are not adequate indicators for measuring the potential environmental impacts of the 360 treated items. 
362 In contrast with unusable cuts, the construction of treated fills accounted for $35 \%$ (i.e.

$36380,000 \mathrm{~m}^{3}$, Table 3) of the engineered earth volume and $33 \%$ (i.e. [59.2] $10^{3} \mathrm{~L}$, Table

364 4) of total fuel consumption. However, treated fills induced $40 \%-65 \%$ (Stripple LCl)

365 and $42 \%-64 \%$ (UPC LCI) of the potential overall $I_{6}$-related environmental impacts

366 (Fig. 3). This discrepancy becomes even more significant when considering the

367 treated sub-base layer, which represents $9 \%$ (i.e. $22,000 \mathrm{~m}^{3}$, Table 3 ) of the

368 engineered earth volume and $11 \%$ (i.e. [20.4] $10^{3} \mathrm{~L}$, Table 4) of total fuel 369 consumption, while inducing 16\%-30\% (Stripple LCI) and 17\%-31\% (UPC LCI) of the

370 potential overall $I_{6}$-related environmental impacts. More specifically, the treated items

371 primarily contributed to the GWP indicator: IGWP relative to the treated sub-base layer

372 and fills equaled $>90 \%$. In comparison, the generation of enriched soils and

373 unusable cuts only amounted to $<1 \%$ and $4 \%-9 \%$ of $\mathrm{I}_{\mathrm{GWP}}$, respectively.

374

\subsection{Potential environmental impacts: quicklime and machine contributions}

An important parameter affecting the $I_{6}$ panel of environmental indicators was the

377 presence / absence of quicklime treatment, thus leading us to compare the

378 contributions of both quicklime (in terms of production, transportation and 379 implementation) and the use of earth engineering machinery (Fig. 4).

381 Regarding energy consumption and emissions of global warming substances, the

382 quicklime treatments represented $77 \%$ (Stripple LCI) and 64\% (UPC LCI) of $\mathrm{IEE}_{\mathrm{EE}}$, and $38391 \%$ (Stripple LCl) and 83\% (UPC LCl) of IGWP, respectively. Calculations have 384 indicated that except for the POCP and TP indicators, the potential environmental 385 impacts of quicklime treatment have invariably originated from the quicklime 386 production step, i.e. $93 \%-87 \%$ of $\mathrm{I}_{\mathrm{EE}}, 98 \%-95 \%$ of $\mathrm{I}_{\mathrm{GWP}}, 88 \%-65 \%$ of $\mathrm{I}_{\mathrm{AP}}$ and $83 \%$ - 
$56 \%$ of $\mathrm{I}_{\mathrm{EI}}$, as obtained from the Stripple and UPC LCls, in this order. For instance,

388 the production step yields carbon dioxide $\left(\mathrm{CO}_{2}\right.$, a low-toxicity substance, i.e. toxic at

389 levels $>1 \%$ in the atmosphere) emissions when limestone is heated. In contrast, the in situ implementation (42\%-45\%) and on-road transportation (14\%-15\%) steps dominated the $\mathrm{I}_{\mathrm{POCP}}$ contributions of quicklime treatment. Distance from the lime kiln

392 measured $\sim 150 \mathrm{~km}$. This observation also was partially true for $\mathrm{I}_{\mathrm{TP}}$. In situ 393 implementation and on-road transportation accounted for respectively $62 \%$ and $21 \%$ 394 of $\mathrm{I}_{\mathrm{POCP}}$ for quicklime treatment when using the Stripple LCI. Yet, these factors only 395 accounted for $<1 \%$ and $2 \%$ when using the UPC LCl.

397 The potential environmental impacts from earth engineering equipment 398 systematically exceeded that of quicklime treatment for $\mathrm{I}_{\mathrm{POCP}}$, i.e. $72 \%$ (Stripple LCI) 399 and 73\% (UPC LCI), respectively (Fig. 4). The $\mathrm{I}_{\mathrm{TP}}$ of machinery only prevailed when 400 using Stripple's quicklime production LCI (79\%, top panel in Fig. 4), whereas the 401 corresponding $\mathrm{I}_{\mathrm{AP}}$ and $\mathrm{I}_{\mathrm{El}}$ only dominated when using the UPC quicklime production 402 LCI (61\% and 66\%, bottom panel in Fig. 4). For these indicators, the associated 403 quicklime treatment contributions of treated fills and the sub-base layer were minimal, 404 i.e. $20 \%-16 \%$ and $46 \%-40 \%$, respectively (Fig. 3). Accordingly, the POCP indicator 405 and, to a lesser extent, $I_{A P}$ and $I_{E I}$ (due to its LCI sensitivity, the use of $I_{T P}$ remains 406 problematic) were affected by machine-related processes such as the in situ 407 movements of excavated earth.

409 In the earthworks field, moved earth is transported from the cuts to fills and/or to the 410 earthwork items. To maintain the frequency of earth movements, the quantity of earth 411 movers has increased with $\bar{L}$ (from 2 to $>8$ dumpers). Hence, fuel consumption 
412 varied markedly among the earthwork items, ranging from $1.410^{3} \mathrm{~L}$ for enriched soils

413 to $4210^{3} \mathrm{~L}$ for treated fills (Table 4). Fuel consumption by earth movers contributed 414 to raising the $\mathrm{POCP}$ indicator through the emission of photochemical ozone 415 precursors (mainly $\mathrm{NO}_{\mathrm{x}}$ and $\mathrm{NMOC}$ ) into the atmosphere. This was apparent from the

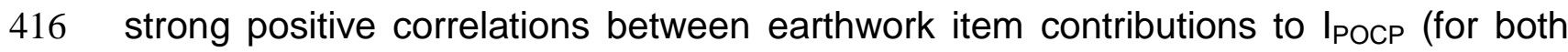
417 the Stripple and UPC LCIs) and the local fuel consumption: $r^{2}=0.95, I_{P O C P}(i)=10$ 418 Fuel $(\mathrm{i})+80$, where fuel is expressed in $10^{3} \mathrm{~L}$ and "i" refers to the given earthwork 419 item. As regards $\mathrm{I}_{\mathrm{AP}}, \mathrm{I}_{\mathrm{EI}}$ and $\mathrm{I}_{\mathrm{TP}}$, the $\mathrm{r}^{2}$ values were $0.46-0.86,0.58-0.91$ and 0.96 $420 \quad 0.23$, in this order.

\section{DISCUSSION}

\subsection{Data robustness for treated and untreated soil comparisons}

424 To strengthen the applicability of these calculated environmental indicators, several key LCA parameters have been verified and validated. For instance, the relevance of selected pollutants with respect to the earthworks field has been examined in order to evaluate the proportion of impacts attributable to the machinery or energy production.

428 The procedures employed for characterizing emissions were considered adequate to assess the credibility (hence uncertainty) ascribed to the chemical flows. Moreover,

430 the contributions of each chemical substance to the various impact categories have 431 been carefully monitored so as to update the current databases.

433 Differences between the considered LCls consisted of system boundaries, a broader array of quicklime production plants, a more complete flow list and technological

435 accomplishments (see Section 2.2.2 and Table 1). Sensitivity analyses indicated that 436 the principal factors responsible for indicator values discrepancies with Stripple, UPC 
or Ecoinvent LCls were: i) technological achievements with respect to lower energy consumption and global warming substance emissions; and ii) more complete flow

439 list (as initiated by ISO 14040-4, 2006 and NF P01-010, 2004 standards), in this 440 order. According to Stripple (2001) and in reading the data shown in Figure 4, a total 441 of $9,240 \mathrm{MJ}$ are consumed and $2,040 \mathrm{~kg}$ of $\mathrm{CO}_{2}$ emitted per ton of quicklime 442 produced. These amounts were about twice the values provided by UPC (2010) or

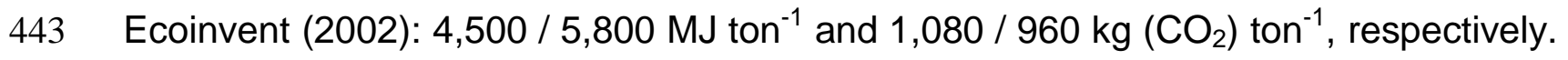
444 The significantly smaller UPC energy consumption and $\mathrm{CO}_{2}$ emissions had however 445 limited the impact on quicklime treatment contributions, as expressed in percentages, 446 which only decreased by $<15 \%$ (Fig. 4). This observation highlights that due to the 447 intrinsically high energy consumption and $\mathrm{CO}_{2}$ emissions during the production step, 448 the contribution of quicklime to the $\mathrm{I}_{\mathrm{EE}}$ and $\mathrm{I}_{\mathrm{GWP}}$ indicators prevails regardless of the 449 preferred life cycle inventory. This finding has been further substantiated by the 450 quicklime production inventories in the Ecoinvent database (quicklime in loose pieces 451 at the plant / quicklime milled loose at the plant, 2000-2002) (Kellenberger et al., 452 2004).

454 Another critical observation is the leap in ITP quicklime treatment contribution upon 455 implementation of the UPC quicklime production LCI (Fig. 4). Such a leap was 456 unexpected since French lime kilns from 2010 would have been expected to offer 457 cleaner production processes than kilns from 2001 (due to the indication of lower 458 energy consumption and $\mathrm{CO}_{2}$ emissions). $99 \%$ of the observed increase actually 459 originated from the PAHs, which were not available in Stripple's LCI (Table 2). PAHs 460 are formed in flames $\left(\mathrm{T}>500^{\circ} \mathrm{C}\right.$, Bittner and Howard, 1981; Frenklach et al., 1984; 461 Marinov et al., 1998), presumably during the calcination of limestone whenever fuel 
462 hydrocarbons are not completely combusted. This finding was confirmed by the fact 463 that the production step accounted for $98 \%$ of $\mathrm{I}_{\mathrm{TP}}$ (UPC LCI) vs. just $18 \%$ of $\mathrm{I}_{\mathrm{TP}}$

464 (Stripple's LCI), i.e. $72010^{3} \mathrm{~kg}$ eq. $1.4 \mathrm{DCB}$ vs. 3,000 kg eq. $1.4 \mathrm{DCB}$, respectively. 465 For the sake of comparison, ITP with the Ecoinvent LCls for quicklime exhibited 466 intermediary values, i.e. $14010^{3} \mathrm{~kg}$ eq. $1.4 \mathrm{DCB}$ (38\% for the production step). It is 467 worth noting that the lack of consistency between the LCls implemented and the high 468 sensitivity to a few key substances undermines the pertinence of multi-pollutant 469 indicators such as ITP. Due to the absence of uncertainties attributed to the data in 470 the literature and the LCls of the materials and construction techniques deployed 471 herein, the results obtained should therefore only be considered as indicative.

\subsection{Natural resource consumption: soil treatment vs. aggregate use}

474 As previously mentioned, quicklime treatments are initially anticipated so as to optimize the use of local materials (e.g. to limit aggregate input) and minimize the output of unusable earth (and thus fuel consumption and surface occupancy). Hence, natural resource conservation (both aggregates and soil) was evaluated in terms of the mass of materials introduced and their related potential environmental impacts.

In the absence of quicklime treatment, the volume of imported aggregates used 481 would have been equivalent to that of the treated earth, i.e. $102,000 \mathrm{~m}^{3}$ (Table 3), 482 which roughly represents 214,200 tons of aggregate (overall average density of the 483 local dry - i.e. $<1 \%$ water content $-0-31.5 \mathrm{~mm}$ calcareous aggregate: 2.1 tons $\mathrm{m}^{-3}$ ) 484 and necessitates the combustion of $132,300 \mathrm{~L}$ of fuel $(122,090 \mathrm{~L}$ for transportation, 485 based on a 20-km distance between the RN7 worksite and an available quarry, plus $48610,200 \mathrm{~L}$ for in situ implementation). Similar calculations have pointed out that if 
considered as waste, the same volume of treated earth would have necessitated the

combustion of $89,050 \mathrm{~L}$ of fuel to be exported and used to construct artificial fills (the

489 mean density of earth is 1.8 tons $\mathrm{m}^{-3}$, and the distance to the waste disposal site is assumed to be close to $10 \mathrm{~km}$ ). The transportation of aggregates and unusable earth also represents 8,930 and $7,650 \mathrm{~km}$ of on-road truck hauling, respectively. The perkilometer fuel consumption for loaded and empty trucks equaled: $0.380 \mathrm{~L} \mathrm{~km}^{-1}$ and $0.304 \mathrm{~L} \mathrm{~km}^{-1}$, respectively. The resulting amounts of materials and their relative contributions to study area natural resource consumption (NRC, in tons) and the $I_{6}$ panel of environmental indicators are displayed in Figure 5. These calculations were based on the French LCls for quicklime production and aggregate extraction by UPC and Jullien et al. (2012), respectively.

Figure 5 shows that the contribution of quicklime exceeds that of aggregates only for $\mathrm{I}_{\mathrm{GWP}}\left(\mathrm{x}\right.$ 2.3) and $\mathrm{I}_{\mathrm{TP}}(\mathrm{x}$ 5.6). This important finding demonstrates that quicklime treatment prevents the consumption of a large amount of materials from quarries $(4,140$ tons of limestone, with 1.77 tons of limestone being calcined per ton of quicklime produced, vs. 214,200 tons of aggregates and 183,600 tons of unusable earth removed from the RN7 site). It also highlights that depending on the indicator, quicklime treatment may cause less loading than the technical aggregate solution on the overall environment $(57 \%, 20 \%, 18 \%$ and $15 \%$ of the aggregate contribution to $I_{E E}, I_{A P}, I_{E I}$ and $I_{P O C P}$, respectively). Comparatively speaking, when using the ECORCE application with Stripple's quicklime production LCI, the $\mathrm{I}_{\mathrm{EE}}$ for quicklime treatment exceeded that of the aggregates by $\sim 9 \%\left(2.310^{7} \mathrm{MJ}\right.$ vs. $\left.2.110^{7} \mathrm{MJ}\right)$, which signifies that due to technological achievements in terms of energy conservation and cleaner production, LCl data must be continuously adapted. A 
512 critical examination of the sensitivity of selected indicators must be undertaken in

513 order to correctly evaluate the potential environmental impacts of the materials and

514 earth construction techniques introduced.

516 Overall, the high $\mathrm{I}_{\mathrm{GWP}}$ and $\mathrm{I}_{\mathrm{TP}}$ values inherent in the quicklime production step (i.e.

517 limestone calcination-induced $\mathrm{CO}_{2}$ and $\mathrm{PAH}$ emissions) raise doubts over the use of quicklime in the field of earthworks. Yet on the other hand, quicklime treatments have dramatically lowered: aggregate consumption, the number of passes for rollers, the volume of unusable earth removed from the RN7 earthworks, the quantity of on/offroad heavy vehicles, and the generation of both noise and chemical compounds, which are responsible for a negative influence on global acidification, eutrophication, photochemical ozone creation and chronic human toxicity indicators.

\subsection{Comparison with the projected RN7 road traffic}

Lastly, the NRC and $I_{6}$ environmental indicators were calculated for the full set of

527 RN7 earthworks (Table 5). The spatial development of RN7 earthworks was not

528 linear; instead, it consisted of smaller earthwork areas, whose locations depended on

529 the natural and technical obstacles that hinder progress of earth engineering

530 equipment, as well as on the geomorphological and mechanical characteristics of

531 local soils. All these areas were eventually merged in order to complete the entire

532 8.9-km long RN7 earthworks project. Accordingly, the calculations were based on

533 data in the log used to manage daily work for the entire site; these data included: i)

534 type, quantity, task and fuel consumption $(1,587,564 \mathrm{~L})$ of the earth engineering

535 machinery; and ii) the volumes of engineered earth and amounts of imported

536 materials for each individual earthwork item (Table 3). The consistency of the $I_{6}$ 
environmental indicator values was ultimately verified, a step that consisted of

538 comparing the relative contributions of earthwork items when using the ECORCE 539 application separately with data for both the entire RN7 earthworks $(8.9 \mathrm{~km} \mathrm{long})$ and 540 the smaller $\left(1.9 \mathrm{~km}\right.$ long) study area. The contributions of earthwork items to the $\mathrm{I}_{6}$ 541 panel of environmental indicators exhibited consistent trends: $0.9<$ item contribution 542 to $I_{6}$ (entire RN7 $\mathrm{m}^{-3}$ ) / item contribution to $\mathrm{I}_{6}$ (study area $\mathrm{m}^{-3}$ ) $<1.4$. This 543 determination corroborates that the newly calculated values of $I_{6}$ environmental 544 indicators and those for the study area were relatively consistent and presumably representative of the whole RN7 scope of earthworks (Table 3).

547 The full RN7 earthworks accounted for $3.510^{7} \mathrm{~kg}$ eq. $\mathrm{CO}_{2}$ (Stripple's LCI), $2.010^{7} \mathrm{~kg}$ 548 eq. $\mathrm{CO}_{2}$ (UPC LCl) or $1.910^{7} \mathrm{~kg}$ eq. $\mathrm{CO}_{2}$ (Ecoinvent LCl). If an aggregate sub-base and aggregate fills had been employed instead of quicklime treatments, then these results would have amounted to: $1.210^{7} \mathrm{~kg}$ eq. $\mathrm{CO}_{2}$ (Table 5). The obtained values were compared to the projected emissions of global warming substances induced by 552 vehicles in covering the $8.9-\mathrm{km}$ long $\mathrm{RN7}$ road. Assuming the RN7 traffic is 553 equivalent to that of the main adjacent road (i.e. $~ 9,000$ vehicles $\mathrm{d}^{-1}$ at $0.13 \mathrm{~L} \mathrm{~km}^{-1}$ of 554 average diesel fuel consumption), then the total emissions of global warming 555 substances (> $97 \%$ as $\mathrm{CO}_{2}$ ) would reach $1.210^{7} \mathrm{~kg}$ eq. $\mathrm{CO}_{2} \mathrm{y}^{-1}$. Despite the 556 uncertainties surrounding the data, this result clearly shows that RN7 road traffic 557 offsets in less than a few years the GWP impact of the entire earthworks project 558 (either for quicklime treatment or aggregate construction technique). Smaller values, 559 i.e. around 2 years or less, were found for the other environmental indicators. 
563 In assessing the potential environmental impacts of typical road earthworks, the 564 contribution of treated earthwork items has typically dominated the $I_{6}$ panel of 565 indicators. The discrepancy between the contribution of quicklime treatment and that 566 of the equipment implemented in situ rendered the engineered earth volume, 567 machine activity and/or their daily fuel consumption inadequate as an accurate gauge 568 of the potential environmental impacts of the earthwork study area. This is likely to be a general feature of all treated earthworks, including road and railway construction.

571 The main findings of the present study have yielded general trends rather than highly 572 accurate indicator values. For instance, quicklime treatment primarily affected the 573 energy consumption and global warming potential indicators. Depending on the 574 selected LCI, these may also drastically increase the chronic human toxicity potential through $\mathrm{PAH}$ emissions during the limestone calcination step. In contrast, machine-

576 induced emissions extensively drove the photochemical ozone creation potential and, 577 to a lesser extent, the eutrophication index and acidification potential.

579 Understanding the main results on this local case relative to the technical choices of 580 soil treatment with quicklime or natural aggregates leads us to draw several 581 conclusions. The treatments served to conserve natural resources (both aggregates 582 and soil) and, as a result, reduced both the emissions of chemical substances and 583 environmental impacts inherent in the aggregate extraction and transportation steps. 584 Further research is needed however to assess the net benefits of quicklime treatment 585 over traditional techniques (like aggregates) in terms of bearing capacity, compaction 586 time and related changes in the thickness of earthwork items. 
588 From an overall standpoint, the calculated potential environmental impacts of the 589 RN7 earthworks stage were roughly equivalent to a few months / years of projected 590 road traffic. This was significantly greater than the impacts of pavement construction 591 and/or maintenance (i.e. a few days of road traffic, data not shown). On the other 592 hand, earthwork items require no maintenance and their service life is expected to be 593 considerably longer, i.e. > 100 years. It is also believed that significant impact 594 mitigation can be achieved by using more recent machinery (e.g. mounted with diesel 595 particulate filters) and improving operating conditions so as to decrease peak 596 consumption and emissions. When viewed in this light therefore, earthworks are a 597 "sustainable" investment.

598 
601 Table 1: System boundaries and assumptions adopted for quicklime production LCls 602 available in three literature datasets. The number of outflows and functional units are 603 also displayed.

604

605 Table 2: List of chemical substances and physicochemical parameters input into the 606 ECORCE application calculations in order to assess the potential environmental 607 impacts of earthwork activity. The compounds underscored and in bold letters were 608 reported in the quicklime production inventories by Stripple and UPC, respectively.

610 Table 3: Summary of data on engineered earth volumes and main material inflows 611 used in the environmental calculations for the 1.9-km long study area. The values in 612 parentheses represent the entire (8.9 km long) RN7 earthworks project.

614 Table 4: Summary of data on in situ earth movements and related fuel consumption 615 introduced into the environmental calculations for the $1.9-\mathrm{km}$ long study area. The 616 values in square brackets pertain to the engineered [moved + locally processed] 617 earth.

619 Table 5: Environmental indicators calculated for the entire $(8.9 \mathrm{~km}$ long) RN7 620 earthworks. The values in parentheses represent the smaller $(1.9 \mathrm{~km}$ long) study 621 area. A distinction is drawn between the impacts for quicklime treatment (with either 622 Stripple's or UPC LCI data) and for aggregate construction techniques. The bottom 623 row indicates the projected annual RN7 road traffic. 
627 Figure 1: Schematic views of the RN7 earthworks site and the smaller study area.

628 The surface of the open (resp. filled) squares in the lateral view were set proportional 629 to the volume of moved earth (resp. quicklime applied). The arrow lengths were set 630 proportional to the average distance traversed by moved earth.

631

632 Figure 2: Data aggregation chart used to calculate the potential environmental 633 impacts of the various items composing the study earthworks site. A distinction is 634 drawn between the materials used and earth engineering equipment deployed (i.e. 635 either earth movers or earth processers) relative to emissions.

636

637 Figure 3: Relative contributions of earthwork items to the $I_{6}$ indicators for the study 638 area (1.9 km long). A distinction was drawn between the values obtained using 639 Stripple's (top panel) and the UPC (bottom panel) quicklime production inventories. 640 Definition of acronyms used for indicators: EE: consumed energy; GWP: global 641 warming potential; AP acidification potential; El: eutrophication index; POCP: 642 photochemical ozone creation potential; and TP: chronic human toxicity potential. 643 644 
645 Figure 4: Relative contributions of soil quicklime treatment and earth engineering 646 machinery, in terms of emissions, to the $I_{6}$ indicators for the study area (1.9 km long). 647 A distinction was drawn between the values obtained using Stripple's (top panel) and 648 the UPC (bottom panel) quicklime production inventories. Definition of acronyms 649 used for indicators: EE: consumed energy; GWP: global warming potential; AP: 650 acidification potential; El: eutrophication index; POCP: photochemical ozone creation 651 potential; and TP: chronic human toxicity potential.

652

653 Figure 5: NRC and $I_{6}$ indicator values of quicklime treatments and aggregate 654 (including unusable earth exportation) construction techniques for the study area (1.9 $655 \mathrm{~km}$ long). The greatest contribution is set equal to $100 \%$. Definition of acronyms used 656 for indicators: EE: consumed energy; GWP: global warming potential; AP: 657 acidification potential; El: eutrophication index; POCP: photochemical ozone creation 658 potential; and TP: chronic human toxicity potential. 